\title{
The sag: A forgotten parameter in need of resurrection?
}

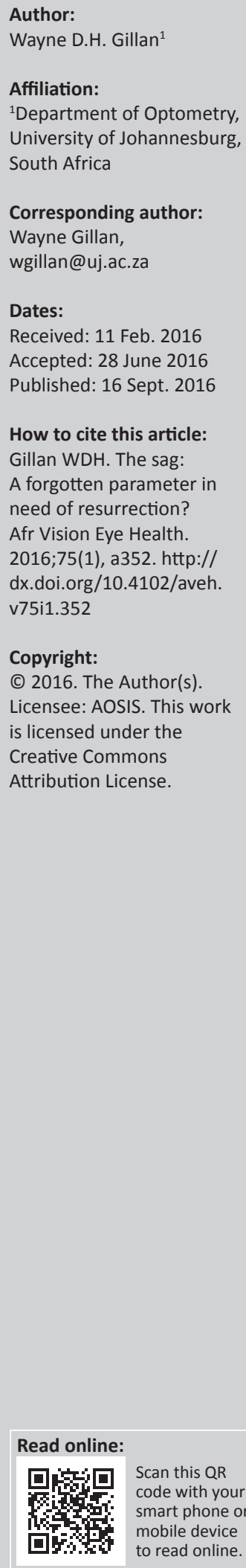

The advent of large-diameter rigid contact lenses (semi-scleral lenses) has necessitated renewed understanding of the concept of 'the sag' of a contact lens and/or cornea. This article reviews the concept of 'the sag' and how to calculate the sag for spherical and aspherical surfaces. Reviews of empirical studies investigating the sag of the eye are presented. Data for normal and keratoconic corneas for sags as measured with an Oculus Keratograph are also included. How to include empirical measurements obtained in practice, in the determination of a first-trial semi-scleral lens, is suggested.

\section{Introduction}

The concept of sagittal height or depth (the sag) of a surface (in this context, usually of lens surfaces) is first introduced to optometry students when they are in their formative years of study. Subjects such as optics, ophthalmic optics and contact lens optics would normally be expected to include the sag, how it is defined and how it is calculated. It is probably safe to say that the majority of us have forgotten most of what we learnt about the sag, especially how to calculate it. The advent of semi-scleral, large-diameter, rigid contact lenses (known as semiscleral, mini-scleral or sometimes even as scleral lenses) has, for those of us who choose to fit these lenses, forced us to dredge our memories, dust off long-forgotten text books (if we still have them) and refresh our understanding of what a sag is and the role it might now play in our fitting of these new large-diameter lenses. A new buzzword in the rigid contact lens world is now 'vault'. Semi-scleral lenses need to 'vault' the cornea, not touching any part of the eye until the lens is on the sclera. Understanding the concept of the sag of both the cornea or eye and the contact lens enables us to better understand the relationship between the cornea and the lens when the lens is on the eye.

\section{The sag: Theory}

Sagittal height (sag) is defined as 'the height or depth of a segment of a circle or a sphere' or 'on an arc the perpendicular distance from the centre of the chord to the arc'. ${ }^{1}$ The derivation ${ }^{2,3,4}$ of the sag formula for a spherical surface is based on Pythagoras' theorem with the sag being calculated using:

$$
S=r-\sqrt{\left(r^{2}-y^{2}\right)}
$$

where $S$ is the sag, $r$ is the radius of the spherical surface and $y$ is half of the chord diameter. So, for a spherical corneal surface having a radius of $8 \mathrm{~mm}$ on a chord of $10 \mathrm{~mm}$, the sag of that cornea would be $1.755 \mathrm{~mm}$ (or $1755 \mu \mathrm{m}$ ). However, the cornea is usually not a spherical surface. The sag formula ${ }^{2,5}$ for an aspherical surface is:

$S=\frac{r-\sqrt{\left(r^{2}-p y^{2}\right)}}{p}$

[Eqn 2]

where $S$ is the sag, $r$ is the radius of the aspheric surface, $p$ (where $p=1-e^{2}$ ) is the shape factor of the aspheric surface and $y$ is half the chord diameter. The same cornea as above having an assumed eccentricity of 0.55 would have a sag of $1.686 \mathrm{~mm}$ (or $1686 \mu \mathrm{m}$ ).

The theoretical ocular sagittal height (cornea and sclera) can be determined mathematically using:

$S=S_{1}+S_{2}-S_{3}$ 


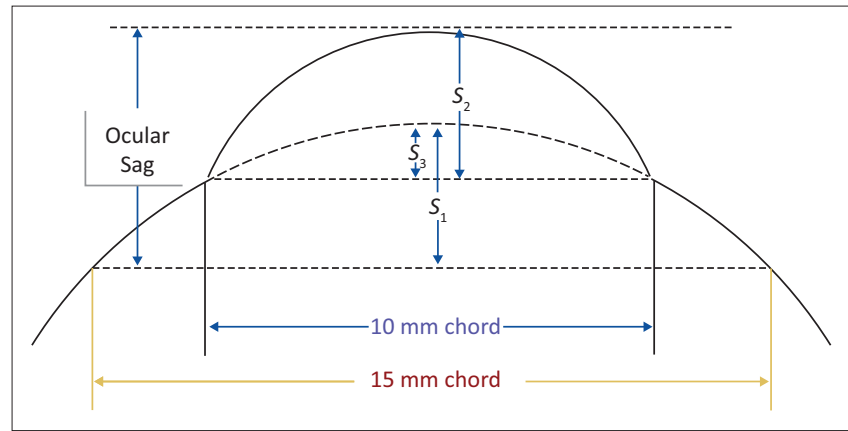

FIGURE 1: Schematic representing the total ocular sag of an eye based on a $15-\mathrm{mm}$ scleral chord and a $10-\mathrm{mm}$ corneal chord $S_{1} S_{2}$ and $S_{3}$ are the relevant sags as discussed in the text.

where $S$ is the total sag and $S_{1}$ (scleral sag on $15 \mathrm{~mm}$ chord), $S_{2}$ (corneal sag on $10 \mathrm{~mm}$ chord), and $S_{3}$ (scleral sag on $10 \mathrm{~mm}$ chord) are the sags indicated in Figure 1.

For the above-mentioned cornea, on a sclera having an assumed (empirically determined ${ }^{6,7}$ ) radius of approximately $13 \mathrm{~mm}$, on a corneal chord of $10 \mathrm{~mm}$ and a scleral chord of $15 \mathrm{~mm}$, the total sag would be approximately $3137 \mu \mathrm{m}$ for the spherical cornea and $3068 \mu \mathrm{m}$ for the aspheric cornea. Unfortunately, the sclera is not symmetrical in its radius, $6,7,8,9,10$ so assumptions should be avoided and other methods have to be used to determine the 'true' sag of a cornea.

\section{The sag: Empirical data}

Sorbara et al., ${ }^{11}$ making use of a Visante optical coherence tomographer (OCT), investigated the ocular sag of 40 normal corneas based on a scleral chord of $15 \mathrm{~mm}$. Measuring the ocular sag at a 15-mm chord might be considered clinically relevant in that many semi-scleral rigid lenses land on the sclera at a chord of approximately $15 \mathrm{~mm}$. The built-in callipers of the instrument were used to measure the chord and the sag of three images for each of the 40 subjects with the mean of the three measures being used to determine the sag for each subject. The mean ocular sag for the 40 subjects in the study by Sorbara et al. ${ }^{11}$ was $3740 \mu \mathrm{m}$. In a pilot study, Sorbara et al. ${ }^{8}$ compared the sagittal depth at 15-mm chords (using the Visante OCT) of 14 randomly selected corneas from 14 normal subjects and 14 keratoconic corneas from 9 keratoconic subjects. In Sorbara et al. ${ }^{8}$ sagittal depth measurements were determined for the steep and flat meridians of each cornea. Table 1 details the findings from this study.

As indicated in Table 1, for the steep meridian (on a 15-mm chord), keratoconic subjects have greater sagittal depths than normal corneas, while for the flat meridian, sagittal depths are not significantly different. Using the horizontal visible iris diameter as the chord (approximately $11.76 \mathrm{~mm}$ ), Sorbara et al. $^{8}$ also determined the sagittal depths for normal and keratoconic corneas (see Table 2).

Using anterior segment OCT, Hall et al. ${ }^{12}$ found a mean corneal sagittal depth for normal corneas of $3130 \mu \mathrm{m}$ using a chord taken between the anterior corneal sulci. A mean sagittal depth of $3725 \mu \mathrm{m}$ was found for normal corneas at a chord of $15 \mathrm{~mm}$ (this finding is similar to those found by Sorbara et al. ${ }^{8,11}$ ), while a mean corneal sag of $1765 \mu \mathrm{m}$ was found using a chord of $10 \mathrm{~mm}$. Kojima et al. ${ }^{13}$ (quoting Achong-Coan ${ }^{14}$ and Copilevitz ${ }^{15}$ ) state that the sags for normal and keratoconic eyes at $10 \mathrm{~mm}$ and $15 \mathrm{~mm}$ chords, respectively, are 1743 and 1960 (10 $\mathrm{mm}$ chord) and $3735 \mu \mathrm{m}$ and $3940 \mu \mathrm{m}$ (15 mm chord).

Unfortunately, most clinicians do not possess a Visante OCT (and they are no longer available) and so having insight into the sag of a cornea at a chord of $15 \mathrm{~mm}$ is difficult to obtain. However, all is not lost. Instrumentation (such as the Oculus Keratograph), which might be more commonly in use in private practice, can provide the sag of a cornea at a chord of $10 \mathrm{~mm}$.

\section{The sag: Keratograph data}

In an attempt to compare our clinic's (Department of Optometry, University of Johannesburg) Oculus Keratograph database with other results, 75 keratoconic and 50 normal corneal topographic measurements were randomly selected from the instrument. The corneal sag, at a chord of $10 \mathrm{~mm}$, was determined for each cornea. The sag data for the normal corneas were found to be normally distributed (KolmogorovSmirnov test, $p>0.10$ ), while the keratoconic data were not normally distributed (Kolmogorov-Smirnov, $p<0.0001$ ). Table 3 shows the descriptive data for the two sets of measurements.

TABLE 1: Sagittal depth measurements of 14 normal versus 14 keratoconic corneas (from Sorbara et al. ${ }^{8}$ ).

\begin{tabular}{lccc}
\hline Meridian & Normal corneas & Keratoconic corneas & $p$-value \\
\hline $\begin{array}{l}\text { Steep } \\
\text { Sagittal depth } 15 \mathrm{~mm}\end{array}$ & 3700 & 3930 & 0.00 * $^{*}$ \\
$\begin{array}{l}\text { Flat } \\
\text { Sagittal depth } 15 \mathrm{~mm}\end{array}$ & 3710 & 3410 & 0.26 \\
\hline $\begin{array}{l}\text { Sagittal depths are indicated for steep and flat corneal meridians at a 15-mm chord. Sagittal } \\
\text { depths are given in micrometres. }\end{array}$ & & \\
*, indicates significant difference. &
\end{tabular}

TABLE 2: Sagittal depth measurements of 14 normal versus 14 keratoconic corneas (from Sorbara et al. ${ }^{8}$ ).

\begin{tabular}{lccc}
\hline Meridian & Normal corneas & Keratoconic corneas & $p$-value \\
\hline Steep & & & \\
Sagittal depth HVID & 2400 & 2790 & $0.001^{*}$ \\
Flat & & & \\
Sagittal depth HVID & 2420 & 2470 & 0.47 \\
\hline
\end{tabular}

Sagittal depths are indicated for steep and flat corneal meridians.

Horizontal visible iris diameter (HVID) is used as the chord. Sagittal depths are in micrometres. *, indicates significant difference.

TABLE 3: Descriptive statistics are given for 50 normal and 75 keratoconic sag measurements.

\begin{tabular}{lcc}
\hline Statistic & Normal corneas $(\boldsymbol{N}=\mathbf{5 0})$ & Keratoconic corneas $(\boldsymbol{N}=\mathbf{7 5})$ \\
\hline Mean (s.d.) & $1706.2(77.5)$ & $1995.9(496.9)$ \\
$95 \% \mathrm{Cl}$ on mean & $1684.2-1728.3$ & $1880.7-2110.9$ \\
Median & 1719.0 & 1864.5 \\
$95 \% \mathrm{Cl}$ on median & $1692.8-1735.2$ & $1838.4-1921.8$ \\
\hline
\end{tabular}

Chord for all measurements was $10 \mathrm{~mm}$.

s.d., Standard deviation; $\mathrm{Cl}$, confidence interval.

Measurements are in micrometres. 

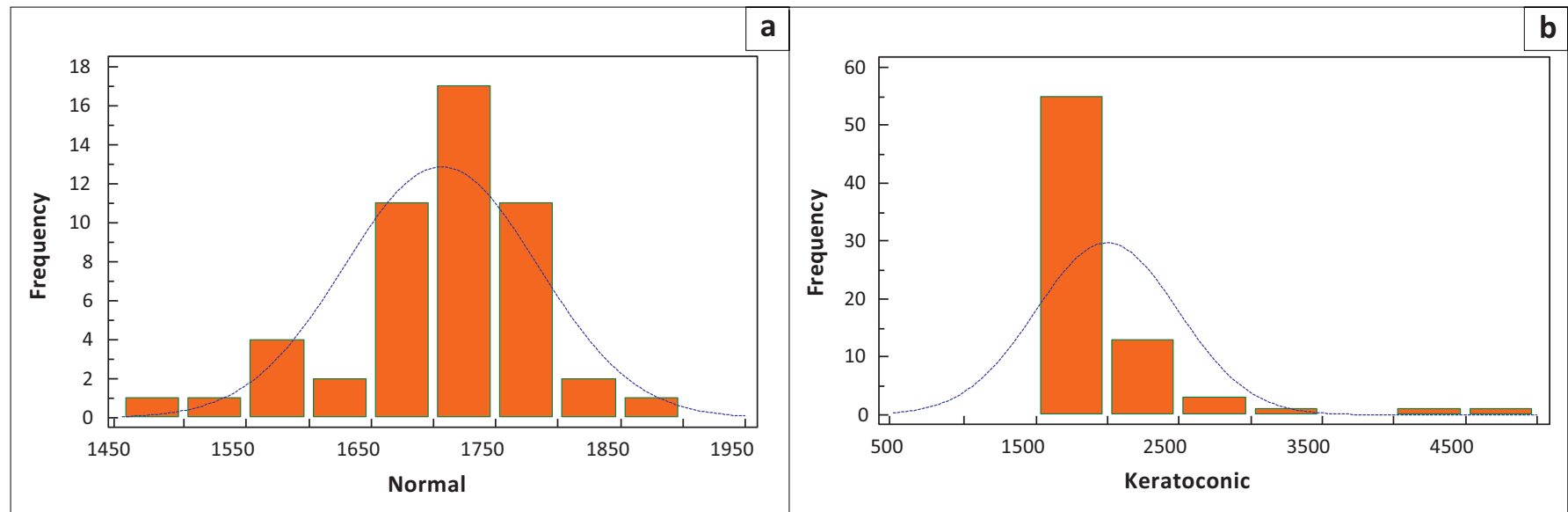

FIGURE 2: Frequency distribution histograms, with normal distribution curve (blue dotted curve) included, are shown. (a) Normal corneas, (b) keratoconic corneas.

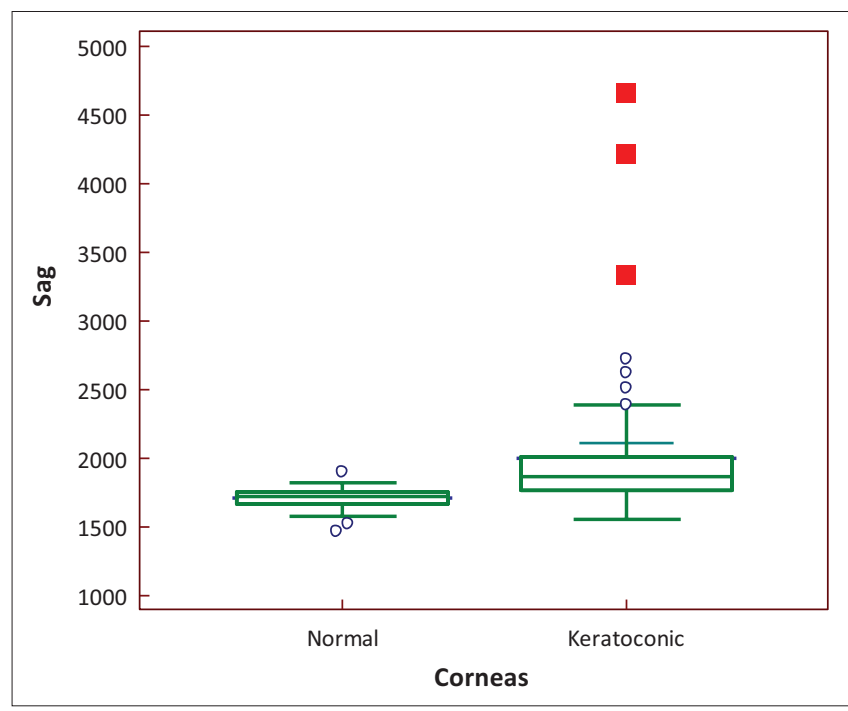

FIGURE 3: Box and whisker plots of sags for 50 normal and 75 keratoconic corneas are indicated. The mean is indicated by the line through each box that represents the $95 \% \mathrm{Cl}$ on the mean (vertical dimensions). The whiskers show the minimum and maximum values, excluding outlying and extreme outliers (indicated by circles and squares, respectively).

Figure 2 ( $a$ and $b$ ) shows frequency distribution histograms with a normal distribution curve superimposed (dotted blue curve) for normal and keratoconic corneas, respectively. Figure 3 shows a box and whisker plot for the normal and keratoconic corneas. The larger variation of the measurements determined for the keratoconic corneas is apparent and is supported by the data in Table 3 (see s.d. for keratoconic corneas). Possible outliers are also more obvious for the keratoconic corneas. The increased variation in sag measurements of keratoconic corneas was also noted by Sorbara et al. ${ }^{8}$

An independent-samples $t$-test was conducted to investigate whether the mean normal sag and the mean keratoconic sag are significantly different. At a $95 \%$ confidence level, the mean sags for the two groups are different $(p<0.001)$.

\section{Conclusion}

If Oculus Keratograph (or similar instrument) data are available (meaning a sag based on a $10 \mathrm{~mm}$ chord), can these data be used to suggest a sag that is indicative of the semi-scleral lens sag that might be used in the fitting of patients? Sags determined from a local Keratograph database (see Table 3) compare favourably with those found by other researchers. ${ }^{8,11,14,15}$ Several publications ${ }^{5,12,13,16,17}$ suggest that the sag difference between a $15-\mathrm{mm}$ chord and a $10-\mathrm{mm}$ chord is approximately $2000 \mu \mathrm{m}$ (for both normal and keratoconic corneas). So if you have the sag of a cornea (based on a $10-\mathrm{mm}$ chord and which can be obtained from an instrument such as the Oculus Keratograph) and you want to get an indication of the sag that you might want to try for your first semi-scleral trial lens, add $2000 \mu \mathrm{m}$ to the sag obtained from the Keratograph (or similar instrument) and then add another $200 \mu \mathrm{m}-400 \mu \mathrm{m}$ for the tear lens or vault thickness that you want and you should have an approximate sag that will vault the patient's cornea. It would need to be investigated whether there is any correlation between the sag suggested by the measurements obtained from an instrument such as the Oculus Keratograph and the actual sag used to successfully vault the patient's cornea.

\section{Acknowledgements Competing interests}

The author declares that he has no financial or personal relationships which may have inappropriately influenced him in writing this article.

\section{References}

1. Cline D, Hofstetter HW, Griffin JR. Dictionary of visual science. 4th ed. Boston, MA: Butterworth-Heinemann; 1997.

2. Douthwaite WA. Contact lens optics and lens design. 3rd ed. London: ElsevierButterworth-Heinemann; 2006.

3. Jalie M. The principles of ophthalmic optics. 2nd ed. London: Association of dispensing opticians; 1974.

4. Jalie M. Ophthalmic lenses and dispensing. 2nd ed. London: ButterworthHeinemann; 2003.

5. Hall L. What you need to know about sagittal height and scleral lenses [homepage on the Internet]. CL Spectrum; 2015 [cited 2015 Dec 05]. Available from: http:// www.clspectrum.com/articlevieweraspx?articlelD=112694

6. Van Der Worp E, Graf T, Caroline PJ. Exploring beyond the corneal borders [homepage on the Internet]. CL Spectrum; 2010 [cited 2015 Dec 05]. Available from: http://www.clspectrum.com/articlevieweraspx?articlelD=104343

7. Choi HJ, Lee S-M, Lee TY, Lee SY, Kim MK, Wee WR. Measurement of anterior scleral curvature using anterior segment OCT. Optom Vis Sci. 2014;91:793-802. 
8. Sorbara L, Maram J, Mueller K. Use of the Visante OCT to measure the sagittal depth and scleral shape of keratoconus compared to normal corneae: Pilot study. J Optom. 2013;6:141-146. http://dx.doi.org/10.1016/j.optom.2013.02.002

9. Van Der Worp E. New technology in contact lens practice [homepage on the Internet]. CL Spectrum; 2010 [cited 2015 Dec 05]. Available from: http://www. clspectrum.com/articlevieweraspx?articleID $=103880$

10. Kojima R, Caroline PJ, Walker M, Kinoshita B, Andre M, Lampa M. Benefits of OCT when fitting specialist lenses [homepage on the Internet]. CL Spectrum; 2014 [cited 2015 Dec 06]. Available from: http://www.clspectrum.com/articlevieweraspx? articlelD $=111805$

11. Sorbara L, Maram J, Fonn D, Woods C, Simpson T. Metrics of the normal cornea: Anterior segment imaging with the Visante OCT. Clin Exp Optom. 2010;93:150-156. http://dx.doi.org/10.1111/j.1444-0938.2010.00472.x

12. Hall LA, Hunt C, Young G, Wolffsohn J. Factors affecting corneoscleral topography Inv Ophth Vis Sci. 2013;54:3691-3701. http://dx.doi.org/10.1167/iovs.13-11657
13. Kojima R, Caroline PJ, Graff T, Kinoshita B, Copilevitz L, Achong-Coan R, et al. Eye shape and scleral lenses [homepage on the Internet]. CL Spectrum; 2013 [cited 2015 Nov 07]. Available from: http://www.clspectrum.com/articleviewer. aspx?articleID $=108179$

14. Achong-Coan R. How do normal and keratoconic eyes differ in shape? Poster presented at the Global Speciality Lens Symposium. 2012 January 27, Las Vegas, NV.

15. Copilevitz L. Are you scared of heights? Poster presented as the Global Speciality Lens Symposium 2012, January 27; Las Vegas, NV.

16. Hall LA, Young G, Wolffsohn JS, Riley C. The influence of corneoscleral topography on soft contact lens fit. Inv Ophth Vis Sci. 2011;52:6801-6806. http://dx.doi. org/10.1167/iovs.11-7177

17. Van Der Worp E. A guide to scleral lens fitting (monograph on line) [homepage on the Internet]. 2010 [cited 2015 Dec 07]. Available from: Pacific University website http:///commons.pacificu.edu/mono/4/ 